geology, climate, soil, vegetation zones, fauna and early history of the islands, a complete flora takes up the greater part of the book. Each species is treated as fully as one could wish, in the present state of knowledge, with keys to all the main groups, and ample line drawings and distribution maps. These maps are of extreme interest, if only in making clear the very limited knowledge we still have of the Galapagos flora. For only the main islands have been at all adequately explored, and even there only the more readily accessible portions. The field is clearly wide open for further exploration-almost anywhere off the main tourist tracks will serve-and with the aid of this book it should no longer be necessary to take specimens of even the commonest plants. Another point: since all the flora has immigrated at some time or other from the mainland, it is only to be expected that fresh plants will be continually arriving. Even in the few years since the field work for this book was completed, it is clear that some ruderal plants have spread more widely. So even in Academy and Wreck Bays, probably the best worked areas in the archipelago, new records can quite easily be made.

RICHARD FITTER

\title{
The Mammals of Arabia, Vol. III, by David L. Harrison. Ernest
} Benn, $\mathrm{f} 15$.

Dr Harrison is to be congratulated on this work culminating in this final volume to crown the whole. Few people have worked so hard, both in the field and at the bench, to collect the material and work out a book of this nature, yet one of his appendices, 'Addenda to Volumes I \& II', shows how much still remains to be done: here are recorded the first specimen of a wild sheep to be discovered in the Arabian peninsula, and that since 1967, and the even more remarkable record of a lesser kudu, also unknown in Arabia, shot by an Arab in South Yemen in the same year; there is also some evidence that cheetahs still survive in the more remote areas. These three discoveries of what are obviously very rare animals show how urgent is the need for the protection of all.

They show too that Dr Harrison has laid a foundation on which others will build as the area becomes more accessible to naturalists, for whom this book will be an essential tool. This makes the more unpardonable the behaviour of the publishers in continuing, despite the criticisms of successive reviewers, to use the offset printing process and cartridge paper: the middle tones get lost and what could otherwise be useful photographs - e.g. of skulls and teeth-are not worth the paper they are printed on. One only has to compare the frontispiece of the newly discovered wild sheep with the same picture printed on the jacket on a coated paper to see what has been lost. As it is, the plates of skulls, etc. are of little use and the author would have been well advised to have discarded photography altogether and given us more of the admirable line drawings which are the most useful illustrations in all three volumes.

This last volume covers the lagomorphs and rodents and follows the layout of the earlier ones, dealing with both the taxonomy and natural history of each species. In some of the notes it is not always clear whether the author is referring to a species or a subspecies, as when he says ( $p$ 607) that the upper incisors of Arvicola terrestris are 'strikingly pro-odont' while the photograph on the opposite page is of a skull of $A$. $t$. persicus much less proodont than some species of that genus.

The three volumes will remain the standard text book on the mammals of Arabia for the next generation or so and will be as essential to the general naturalist as to the taxonomist. The price was high for the first two volumes, 
$£ 7$ apiece, but this one will be quite out of reach of most individuals. It is much to be hoped, however, that it will get a wide circulation in Arabia so that those in authority may learn how interesting is the mammalian fauna of their region and of their responsibility for its conservation: that they could not have done had it not been for Dr Harrison's work.

CRANBROOK

The Serengeti Lion, by George Schaller. Chicago UP, £5.65. The Spotted Hyena, by Hans Kruuk. University of Chicago Press, £6.75.

George Schaller is exceptional among wildlife biologists. He persists in selecting distant and difficult subjects, tackles them in a scientific manner requiring the utmost concentration, and then, in record time, writes up his results into book form. The Serengeti Lion is no exception to the trend; indeed, it is his most exhaustive work to date.

He covers the lion's behaviour and ecology, with a chapter each on the leopard, cheetah and hunting dog, and a summary on predation. Many of his behavioural findings are entirely new to science. For example lions can be divided into resident and nomadic groups, the latter often ranging over areas of more than $4000 \mathrm{sq} \mathrm{km}$. The resident prides have a closed social system in which all lionesses are genetically related; the nomadic groups are open, with animals joining and leaving at intervals.

Special attention is given to the subject of predator-prey relationships, and the variety of anti-predator responses he observed are particularly interesting. Small prey such as reedbuck and bushbuck or young of gazelle or eland often escaped lions by crouching motionless, while larger, more conspicuous prey preferred to flee. The larger the prey the closer it would allow lions to approach before taking to flight. Surprisingly, although several authors have stated that lions approach their prey against the wind so as to escape detection, Schaller, after diligently recording the wind direction in 300 lion hunts, was unable to find any evidence of this.

Unfortunately the photographs, tables and text are divided into separate sections, with the result that every time one of the 43 photographs or 79 tables is referred to in the text the reader has to flip forwards or backwards to find it.

This book is to be highly recommended for both the serious wildlife scientist and student, and the interested layman who prides himself on having the ultimate that has been written to date on what there is to know about lions.

Hans Kruuk's book undoubtedly the most comprehensive ever written on the subject, is one of a scientific series on wildlife behaviour and ecology, but considerable effort has been made to find a satisfactory compromise between the lay reader and the student. The text is not difficult to follow. The author backs his statements up with data, but has done his best to express these in simply constructed chi diagrams and histograms, rather than in complicated tables. The numerous illustrations include nearly 60 photographs, chi squares and other statistical proofs, of interest primarily to scientists and wildlife students, have been discreetly reduced to footnotes, so as not to interfere with the flow of the text.

There is plenty to interest the general reader. Who, for instance, would have thought that the hyena's equivalent of a dog burying a bone is to carry a hunk of carcass to the nearest waterhole or lake and drop it in-a very practical solution to the problem of protecting carcass remains from vultures, lions and the like. Kruuk shows that hyenas have a 